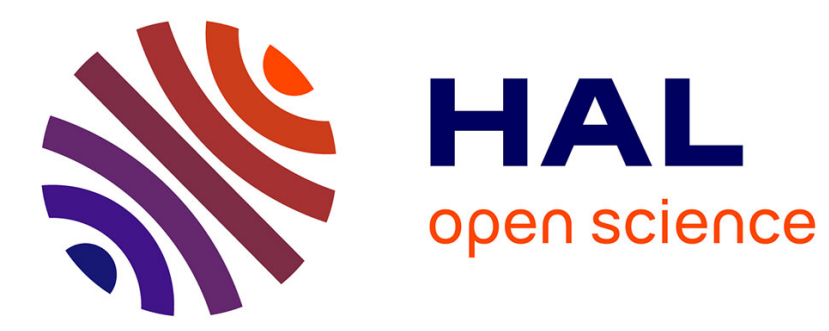

\title{
Copy number variations are not modifiers of phenotypic expression in a pair of identical twins carrying a mutation
}

A. Lasa, T. Ramón y Cajal, G. Llort, J. Suela, J. C. Cigudosa, M. Cornet, C. Alonso, A. Barnadas, M. Baiget

\section{To cite this version:}

A. Lasa, T. Ramón y Cajal, G. Llort, J. Suela, J. C. Cigudosa, et al.. Copy number variations are not modifiers of phenotypic expression in a pair of identical twins carrying a mutation. Breast Cancer Research and Treatment, 2010, 123 (3), pp.901-905. 10.1007/s10549-010-0877-0 . hal-00523666

\section{HAL Id: hal-00523666 https://hal.science/hal-00523666}

Submitted on 6 Oct 2010

HAL is a multi-disciplinary open access archive for the deposit and dissemination of scientific research documents, whether they are published or not. The documents may come from teaching and research institutions in France or abroad, or from public or private research centers.
L'archive ouverte pluridisciplinaire HAL, est destinée au dépôt et à la diffusion de documents scientifiques de niveau recherche, publiés ou non, émanant des établissements d'enseignement et de recherche français ou étrangers, des laboratoires publics ou privés. 
Copy number variations are not modifiers of phenotypic expression in a pair of identical twins carrying a $B R C A 1$ mutation.

A. Lasa ${ }^{1}$, T. Ramón y Cajal ${ }^{2}$, G. Llort ${ }^{3}$, J. Suela ${ }^{4}$, JC. Cigudosa ${ }^{4}$, M. Cornet ${ }^{1,5}$, C. Alonso ${ }^{2}$, A. Barnadas ${ }^{2}$, M. Baiget ${ }^{1,5}$.

1. Genetics Department. Hospital Sant Pau. Autonomous University of Barcelona. Spain

2. Clinical Oncology Department. Hospital Sant Pau. Autonomous University of Barcelona. Spain

3. Clinical Oncology Department. Corporació Parc Taulí. Sabadell. Barcelona, Spain. 4. NIMGenetics, Madrid, Spain. 5. U-705 CIBERER.

Correspondence to:

Dr. Montserrat Baiget

Servicio de Genética

Hospital de la Santa Creu i Sant Pau

Avda. Padre Claret, 167

08025 Barcelona

Phone: +34 932919194

Fax: +34 932919494

e-mail: mbaiget@santpau.cat 


\begin{abstract}
Mutations in BRCA1 and BRCA2 genes confer a high risk of breast and ovarian cancer but the incomplete penetrance of these mutations suggests that other genetic and/or environmental factors may modify this risk. We present a family where all affected members carried a mutation in the BRCAl gene and the index case had suffered from cancer twice in the last 27 years whereas her monozygotic twin sister, also a carrier of the mutation, remained healthy. As copy number variants (CNVs) contribute to phenotypic diversity, a comparative genomic hybridization array $(\mathrm{CGH})$ was performed to see whether the differences in the CNV profile were a modifier factor of the phenotype in our monozygotic twins. Our results show that differences in the CNVs profile were not the cause of the extremely variable penetrance observed in our MZ twin. The search for an explanation should not therefore be limited to genetic changes at the level of the DNA sequence.
\end{abstract}

KEYWORDS: $B R C A 1, B R C A 2$, copy number variation, monozygotic twins

\title{
INTRODUCTION
}

Breast cancer is the most frequent neoplasia among women in industrialized countries. While most breast cancers are sporadic, between 10 and $15 \%$ occur in individuals with a hereditary predisposition [1]. Developments in molecular genetics have enabled the identification of mutations in two genes, BRCA1 (OMIM 113705) and BRCA2 (OMIM 600185). Mutations in these genes are of high penetrance and are considered to increase the risk for hereditary breast and ovarian cancer [2, 3]. The breast cancer risk for carriers of such mutations has been estimated to range from 40-87\% by age 70 [46]. Although much attention has been given to understanding the role of these genes, the incomplete penetrance of their mutations suggests that other genetic and/or environmental factors may modify the risk of developing breast cancer. However, linkage analysis and segregation studies have failed to identify additional major genes with similar effects to BRCAl and BRCA2 [7]. Another hypothesis is that susceptibility is conferred by a large number of loci, each with a small effect on breast cancer risk [8]. Several studies have identified variants in DNA repair genes, such as CHEK2, ATM, BRIPI and PALB2, associated with an increased breast cancer risk, but these variants are rare in the studied populations [911]. Although recent genome-wide association studies (GWA) suggest an elevated breast cancer risk at several candidate loci $[12,13]$, most variability in the risk for $B R C A 1$ and $B R C A 2$ carriers remains unexplained.

Results from several studies have shown that environmental and lifestyle factors, breastfeeding and mammographic density $[14,15]$ are also likely to play a role in the heterogeneity of the disease 
among these carriers. In one study [16], parity appeared to be associated with protection from breast cancer in women with mutations in BRCA1 and BRCA2.

In 1997, we reported the results of $B R C A 1 / 2$ mutation screening in a family at high risk of breast and ovarian cancer [17]. We found an insertion of four base pairs in exon 2 of BRCAl (189insTGTC). All affected members carried the mutation and, surprisingly, the index case had had cancer twice in the last 27 years whereas her monozygotic twin sister, also a carrier of the mutation, had remained healthy. As it is assumed that monozygotic (MZ) twins are genetically identical, any variations between them may be due to environmental factors or epigenetic differences. However, age at menarche, contraceptive use, pregnancies, hormone therapies, history of smoking and drinking, environmental exposures, exercise habits, diet and lifestyle in these twins were almost identical. Both twins had similar menstrual and reproductive histories (each had two sons of similar ages).

A recent and important development in human genetics has been the discovery of large structural variations that affect copy number of DNA segments occurring both in phenotypically normal subjects and in individuals with disease [18]. Copy number variants (CNVs) are insertions, deletions and duplications of genomic sequences ranging from a kilobase to multiple megabase pairs in length. This variation in DNA copy number is a significant source of variability in inheritance and can have a close relationship with the expression of a particular phenotype [19]. Redon et al [20] suggest that the total amount of sequence variation involving CNVs between two normal subjects is higher than that for singlenucleotide polymorphisms (SNPs).

In a recent paper, Bruder et al [21] studied 19 pairs of MZ twins, with either concordant or discordant phenotype. They performed a genome-wide CNV analyses and showed that although MZ twins possess nearly identical genomes, the DNA copy number profile differ.

These data prompted us to study whether the differences in the CNV profile are a modifier factor of the extremely variable penetrance observed in our MZ twins. 


\section{PATIENTS AND METHODS}

\section{Family description}

Figure 1 shows the family pedigree. The index case (III:11), who is presently 61 years old, developed breast cancer when she was 32 years old and ovarian cancer when she was 39. She has two aunts with breast cancer (II:4 and II:9) and an uncle with prostate cancer (II:1). Two cousins had breast cancer at 50 (III:5) and 44 years old (III:16), respectively, and another cousin had ovarian cancer at age 58 (III:7). The proband had two further relatives with breast cancer (IV:2 and IV:4) and one with ovarian cancer (IV:7), all diagnosed between 35 and 40 years of age.

All affected members carried an insertion of four base pairs in exon 2 of the BRCA1 gene at position 189 (189insTGTC). Non-affected members were non-carriers, with two exceptions: II:7 (the father of the index case) and III: 12 (her monozygotic twin). While III:11 has suffered from cancer twice, III:12 has remained healthy according to the results of annual mammographies.

\section{Sample Collection}

DNA was extracted from peripheral blood nucleated cells by the salting out procedure [22]. Written informed consent was obtained and the study was approved by the Institutional Ethics Committee.

\section{Multiplex Ligation-dependent Probe Amplification analysis (MLPA)}

The MLPA procedure was carried out with the BRCA1 P002-B1 probe mix and P045B BRCA2/CHEK2 probe mix according to the manufacturer's instructions (MRC Holland, The Netherlands). Amplification products were separated by capillary electrophoresis on an ABI 3100 Genetic Analyzer (Applied Biosystems, Foster City, CA) and data were analyzed using the software Coffalyser v8.0 (www.mlpa.com).

\section{Comparative Genomic Hybridization array (CGH)}

Agilent Human Genome CGH 244k microarray platform (Agilent Technologies, Santa Clara, CA, USA) was used for $\mathrm{CGH}$ array analysis. This array spans the entire human genome at a median resolution $\sim 8.9 \mathrm{~Kb}$. We used Promega Male Human genomic DNA (Promega, Madison, WI, USA) as hybridization control. Hybridization was carried out following the manufacturer's protocols. Image scanning was performed using an Agilent Scanner and microarray data were extracted using Agilent Feature Extraction v10.1 software. Data analysis and visualization were performed using Agilent DNA Analytics v4.0.76 Software.

Copy number altered regions were detected using the Z-score (set as 4) and ADM-2 (set as 6) statistics provided by DNA Analytics. Copy number polymorphisms in the altered regions were detected using the data available in the Database of Genomic Variants [18].

After these hybridizations, an across hybridization was made to compare samples between the twins. 


\section{RESULTS and DISCUSSION}

An identical, normal MLPA profile for the BRCA1 and BRCA2 genes was observed in the DNA samples of both twins, indicating that no gross rearrangement was present in either sister.

Using a first Agilent 244k array-CGH, we detected an identical pattern of copy number variations in both cases, and several polymorphisms, detailed in Table 1. In the affected twin we also observed a possible deletion of $35 \mathrm{Mb}$ located in 17q21.31 with genomic axis chr17: 38710043-39095187 (Figure 2A). This genomic region contains several genes of interest (ARL4D, DHX8, ETV4 and MEOX1). This deletion showed a statistical value below the recommended criterion but considering its location, we compared each twin with her co-twin to confirm or exclude this finding. Figure 2B shows a normal pattern in this region that excludes the presence of the suspected deletion. In light of this result we conclude that as there is no sequence variation in the genome in our MZ twins, another non-hereditary modifier factor may explain the discordant phenotype.

Complex diseases and traits are influenced by a combination of genetic and environmental risk factors, some of which may be known, and many of which are unknown. In breast cancer, a family history of the disease is one of the most important risk factors. Concordance comparisons between monozygotic and dizygotic pairs of twins have provided information on whether the familial pattern is due to environmental or hereditary influences [23]. As MZ twins are genetically identical, genetic susceptibility should be reflected in a high disease concordance. In contrast, and to our knowledge, this is the first report of MZ twins with a discordant phenotype and carriers of an identical BRCA1 mutation. The risk of BRCA1 or BRCA2 mutation carriers developing breast cancer can vary substantially depending on modifier factors such as the influence of other susceptibility genes or environmental agents. Antoniou and Easton [24] reviewed pedigree analysis, phenotype studies, linkage and association studies in search of evidence for breast cancer susceptibility genes. They hypothesized that susceptibility to breast cancer is mediated through variants in many genes, each conferring a moderate risk of the disease. Knowing that the genetic background of our MZ twins is identical, differences in additional genes would not explain their discordant phenotypes. As lifestyle and menstrual and reproductive histories are almost identical in our twins, the role of environmental factors as modifiers of the phenotype can also be ruled out.

The findings of Bruder et al concerning CNVs and phenotypically discordant MZ twins led us to search for copy number variation in the genome that could have protected the healthy twin against the development of cancer. For this purpose, we used the Agilent Human Genome CGH 244k microarray platform and found no sequence variation involving CNVs. Considering that CNV differences among MZ twins represent an extreme example of mosaicism, it would have been of interest to analyze another source of DNA such as normal breast and/or ovarian epithelial cells. Unfortunately, neither of these tissues was available.

Our results show that, at least in the female twins described here, differences in the CNVs profile are not the cause of the different phenotype. The search for an explanation should not therefore be limited to genetic changes at the level of the DNA sequence. We should also consider epigenetic changes identified in cloned animals [25] and in groups of monozygous twin sisters [26, 27], as well as other phenomena 
that could affect expression of identical genes, such as alterations in microRNAs or differential allelic expression,

If risk-modifying factors are identified we will be able to provide mutation carriers with knowledge about what they can do to reduce their cancer risk. More importantly, incorporating these factors into penetrance estimation will lead to more accurate risk modelling and therefore permit better informed genetic counselling in the future.

\section{FIGURE LEGENDS}

Figure 1.- Pedigree of the family. Br: breast cancer; Ov: Ovarian cancer; Pr: Prostate cancer. Carriers are indicated by $(+)$ and non-carriers by $(-)$.The red square indicates the index case.

Figure 2.- A: CGH pattern showing the potential deletion in the 17q21.31 genomic region. B: Pattern of this region in the across hybridization CGH array.

Table 1. Observed polymorphism. 


\section{REFERENCES}

1. Collaborative Group in Hormonal Factors in Breast Cancer (2001) Familial breast cancer: collaborative reanalysis of individual data from 52 epidemiological studies including 58,209 women with breast cancer and 101,986 women without the disease. Lancet 358(9291):1389-1399

2. Miki Y, Swensen J, Shattuck-Eidens D, Futreal PA, Harshman K et al (1994) A strong candidate for the breast and ovarian cancer susceptibility gene BRCA1. Science 266(5182):66-71

3. Wooster R, Bignell G, Lancaster J, Swift S, Seal S et al (1995) Identification of the breast cancer susceptibility gene BRCA2. Nature 378(6559):789-92

4. Antoniou A, Pharoah PD, Narod S, Risch HA, Eyfjord JE et al (2003) Average risks of breast and ovarian cancer associated with $B R C A 1$ or $B R C A 2$ mutations detected in case Series unselected for family history: a combined analysis of 22 studies. Am J Hum Genet 72(5):1117-30

5. Begg CB, Haile RW, Borg A, Malone KE, Concannon P et al (2008) Variation of breast cancer risk among BRCA1/2 carriers. JAMA 299(2):194-201

6. Milne RL, Osorio A, Cajal TR, Vega A, Llort G et al (2008). The Average Cumulative Risks of Breast and Ovarian Cancer for Carriers of Mutations in BRCA1 and BRCA2 Attending Genetic Counseling Units in Spain. Clin Cancer Res 14(9):2861-9

7. Smith P, McGuffog L, Easton DF, Mann GJ, Pupo GM et al (2006) A genome wide linkage search for breast cancer susceptibility genes. Genes Chromosomes Cancer 45(7):646-55

8. Pharoah PD, Antoniou A, Bobrow M, Zimmern RL, Easton DF, Ponder BA (2002) Polygenic susceptibility to breast cancer and implications for prevention. Nat Genet 31(1):33-6

9. Rahman N, Seal S, Thompson D, Kelly P, Renwick A et al (2007) PALB2, which encodes a BRCA2interacting protein, is a breast cancer susceptibility gene. Nat Genet 39(2):165-7

10. Renwick A, Thompson D, Seal S, Kelly P, Chagtai T et al (2006) ATM mutations that cause ataxiatelangiectasia are breast cancer susceptibility alleles. Nat Genet 38(8):873-5

11. Meijers-Heijboer H, van den Ouweland A, Klijn J, Wasielewski M, de Snoo A et al (2002) Lowpenetrance susceptibility to breast cancer due to CHEK2(*)1100delC in noncarriers of BRCA1 or BRCA2 mutations. Nat Genet 31(1):55-9

12. Hunter DJ, Kraft P, Jacobs KB, Cox DG, Yeager M et al (2007) A genome-wide association study identifies alleles in FGFR2 associated with risk of sporadic postmenopausal breast cancer. Nat Genet 39(7):870-4

13. Easton DF, Pooley KA, Dunning AM, Pharoah PD, Thompson D et al (2007) Genome-wide association study identifies novel breast cancer susceptibility loci. Nature 447(7148):1087-93

14. Andrieu N, Goldgar DE, Easton DF, Rookus M, Brohet R (2006) Pregnancies, breast-feeding, and breast cancer risk in the International BRCA1/2 Carrier Cohort Study (IBCCS). J Natl Cancer Inst 98(8):535-44

15. Mitchell G, Antoniou AC, Warren R, Peock S, Brown J (2006) Mammographic density and breast cancer risk in BRCA1 and BRCA2 mutation carriers. Cancer Res 66(3):1866-72.

16. Milne RL, Osorio A, Ramón y Cajal T, Baiget M, Lasa A et al (2010) Parity and the risk of breast and ovarian cancer in BRCA1 and BRCA2 mutation carriers. Breast Cancer Res Treat 119(1):221-32 
17. Diez O, Brunet J, Sanz J, del Rio E, Alonso MC, Baiget M (1997) Differences in phenotypic expression of a new BRCA1 mutation in identical twins. Lancet 6(9079);350:713

18. Iafrate AJ, Feuk L, Rivera MN, Listewnik ML, Donahoe PK et al (2004) Detection of large-scale variation in the human genome. Nat Genet 36(9);949-951

19. Itsara A, Cooper GM, Baker C, Girirajan S, Li J et al (2009) Population analysis of large copy number variants and hotspots of human genetic disease. Am J Hum Genet 84(2):148-61

20. Redon R, Ishikawa S, Fitch KR, Feuk L, Perry GH et al (2006) Global variation in copy number in the human genome. Nature 444(7118):444-54

21. Bruder CE, Piotrowski A, Gijsbers AA, Andersson R, Erickson S et al (2008) Phenotypically concordant and discordant monozygotic twins display different DNA copy-number-variation profiles. Am J Hum Genet 82(3):763-71

[22] Miller SA, Dykes DD, Polesky HF (1988) A simple salting out procedure for extracting DNA from human nucleated cells. Nucleic Acids Res 16(3):1215

[23] Lichtenstein P, Holm NV, Verkasalo PK, Iliadou A, Kaprio J et al (2000) Environmental and heritable factors in the causation of cancer: analyses of cohorts of twins from Sweden, Denmark, and Finland. N Engl J Med 343:78-84

[24] Antoniou AC and Easton DF (2006) Models of genetic susceptibility to breast cancer. Oncogene 25(43):5898-5905

[25] Humpherys D, Eggan K, Akutsu H, Hochedlinger K, Rideout et al (2001) Epigenetic instability in ES cells and cloned mice. Science 293:95-7.

[26] Fraga MF, Ballestar E, Paz MF, Ropero S, Setien F et al (2005) Epigenetic differences arise during the lifetime of monozygotic twins. Proc Natl Acad Sci USA 102(30):10604-9

[27] Singh SM, Murphy B, O'Reilly R (2002) Monozygotic twins with chromosome 22q11 deletion and discordant phenotypes: updates with an epigenetic hypothesis. J Med Genet 39(11):e71. 


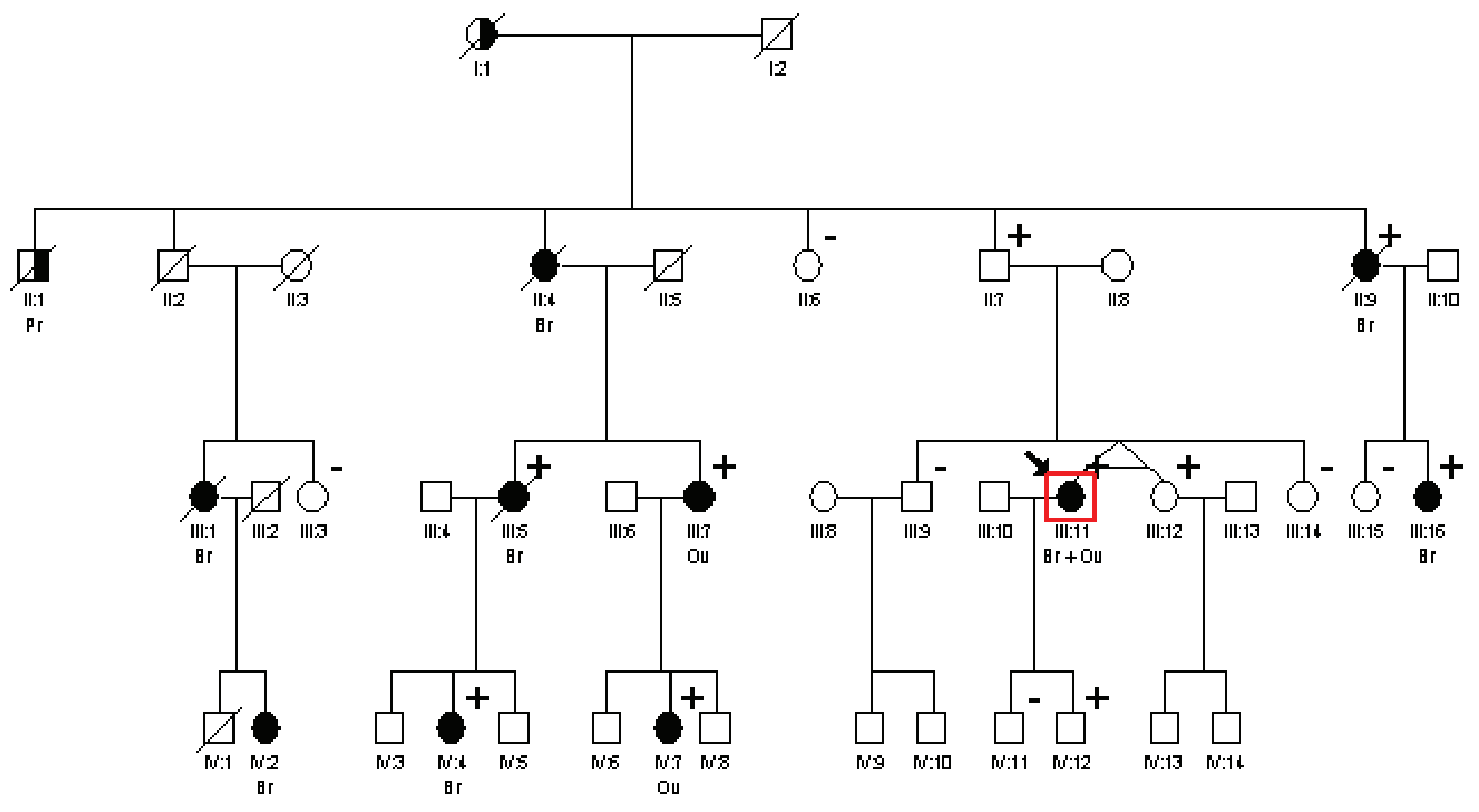


Figure 2

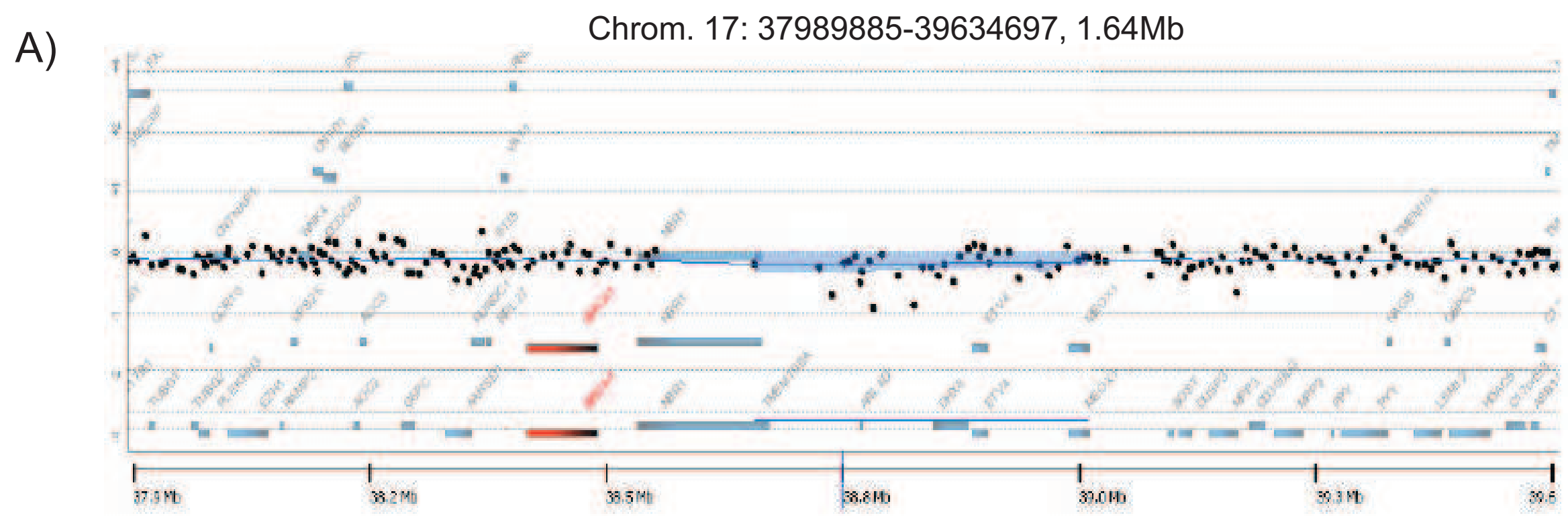

B)

$$
\text { Chrom.17: 37989885-39634697, 1.64Mb }
$$

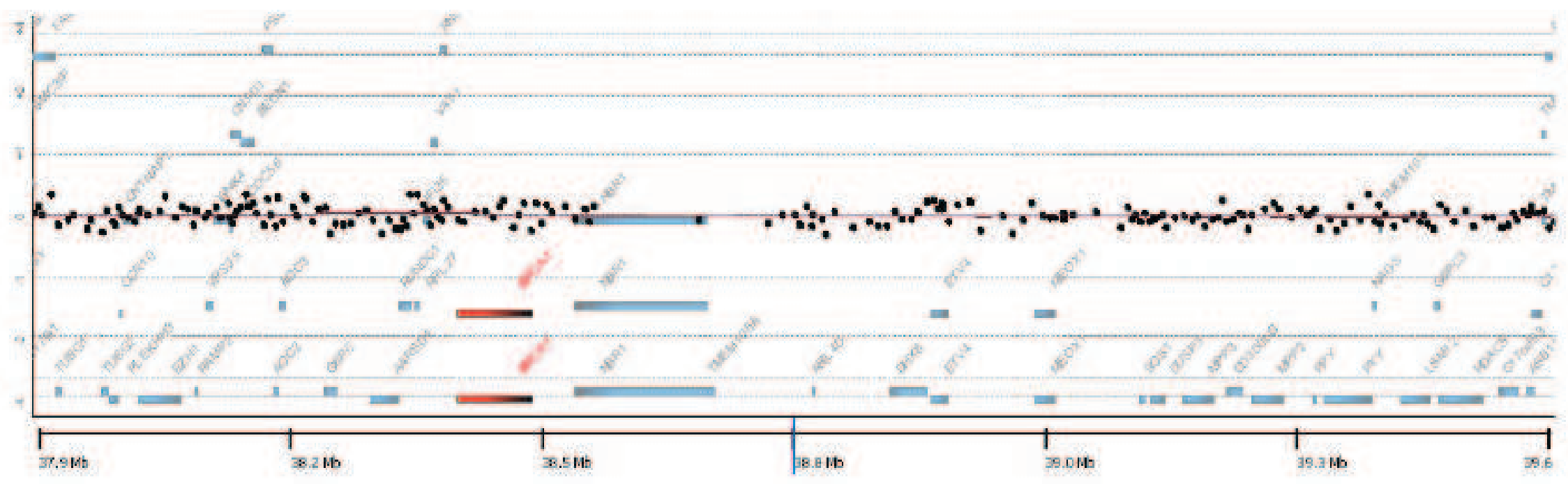

